\title{
EL SOLÓN DE ARISTÓTELES EN LA CONSTITUCIÓN DE LOS ATENIENSES
}

\author{
HÉCTOR GARCÍA CATALDO \\ P. UNIVERSIDAD CATÓLICA DE VALPARAÍSO. Chile
}

\begin{abstract}
Resumen: En esta exposición nos proponemos mostrar la imagen que Aristóteles nos presenta acerca de Solón en la interpretación que nos ha plasmado en la primera parte - de las partes conservadas - en su Athenaíon Politeía. Complementamos esta imagen del poeta-político, recurriendo tanto al contenido de los poemas (elegías) que conservamos del propio Solón, como a otras obras del estagirita en las que destaca el pensamiento político soloniano.
\end{abstract}

Palabras clave: Aristóteles, Athenaíon Politeía, Solón, pensamiento, poesía, política.

\section{ARISTOTLE'S SOLON IN THE ATHENIAN CONSTITUTION}

\begin{abstract}
Abstract: In this exposition we intend to show the image Aristotle gives of Solon in the interpretation of the first part -of those remaining- of his Athenaion Politeia. We complement this image of the poet-politician turning to the content of the poems (elegies) we have of Solon himself, as well as to the other works of the Stagirite where he underlines the Solonian political thought.
\end{abstract}

Key words: Aristotle, Athenaion Politeia, Solon, thought, poetry, politics

Recibido: 5.07.2016 - Aceptado: 29.09.2016

Correspondencia: Héctor García Cataldo

Email: hgarcia@ucv.cl-hgcataldo@hotmail.com

Licenciado en Filología Clásica con Opción Helénica y Latina. Magister en Historia con Mención en Historia Europea y Doctor en Filosofía. Profesor en Instituto de Filosofía de la Pontificia Universidad Católica de Valparaíso. Tel. 032-2274391; Universidad de Chile, Tel. 02-2392292; Universidad de Playa Ancha y Universidad de Talca, sede Santiago. 


\section{Presentación}

7 al como se señala en el título, lo que nos proponemos es mostrar la imagen que Aristóteles nos presenta acerca de Solón en la interpretación que nos ha plasmado en la primera parte - de las partes conservadas - en su Athenaíon Politeía.

Más allá de los problemas que habría que resolver al respecto sólo me limito a señalar que por el momento no me haré cargo de los problemas que dicen relación con las fuentes literarias que hay detrás de la investigación del estagirita en torno a Solón, que habría que proyectar a toda la investigación histórica que emprende Aristóteles en el estudio de la institucionalidad política del mundo heleno y muy en especial respecto de la evolución del pensamiento institucional jurídico entre los atenienses. No obstante, sí nos interesa destacar el punto de vista que creemos es el que el propio filósofo emplea metodológicamente para representar el pensamiento del poeta-político, i. e., el análisis que parte en la propia obra poética de Solón ${ }^{1}$. De modo que nuestra lectura metodológicamente considera tanto el documento de la 'Constitución' como las elegías y yambos, tomados de la propia obra soloniana; además de cotejar informaciones que nos entrega Aristóteles en el marco global de su pensamiento político, expresado en La Política.

$1 \quad$ Al estudiar las obras de Aristóteles, especialmente, su Poética, Política y en particular la Athenaion Politeia da la impresión que el recurso metodológico de investigación cobra vital importancia, al respecto remito a dos importantes trabajos: G. Mathieu, Aristote. Constitutiond'Athènes. Essai sur la méthode suivie par Aristote dans la discussion des textes. Paris, 1915; R. Weil, "Philosophie et Histoire. La vision de l'histoire chez Aristote", en Entretiens sur l'antiquité classique, XI, VandoeuvresGenève. Fond. Hardt 1964 [1965], sin olvidar a W. Jaeger, Aristóteles: bases para la historia de su desarrollo intelectual. Fondo de Cultura Económica. México, segunda reimpresión, 1992. 


\section{La Athenaion Politeía ${ }^{2}$.}

Esta obra de Aristóteles es probablemente uno de los últimos descubrimientos acerca de sus trabajos de los tiempos del Perípatos. Vestigios de la obra comenzaron a aflorar hacia fines de la última década del siglo XIX, en 1880, cuando el profesor F. Blass, en la revista Hermes dio a la publicidad un papiro que se conservaba en un Museo de Berlín. Un año más tarde, en 1881, el profesor Th. Bergk, en Rheinischen Museum, publica un artículo sobre dicho papiro, atribuyendo la paternidad del mismo a Aristóteles. Ese mismo año el profesor H. Diels se referirá al hallazgo en un artículo que titula: "Über die

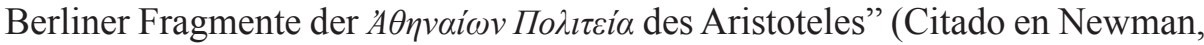
W.L., 1950: 376). Sin embargo, diez años más tarde este hallazgo se vería plenamente refrendado por otro descubrimiento papirológico que provenía de las arenas del desierto egipcio, se trataba nada menos que de la Constitución de los atenienses, que fue dado a la publicidad en 1891 por Sir Frederick G. Kenyon, y que fue conocido desde entonces como el papiro de Londres ${ }^{3}$. Para resumir, investigaciones posteriores han concluido que este descubrimiento venía a ser el libro primero de una colección de 158 Constituciones, escrito por la propia mano de Aristóteles con vistas a su publicidad y que por referencias internas del documento, la obra no se habría publicado antes del 329/8 a. de C., de modo que se puede estimar que ésta haya sido una de las últimas obras con vistas a la publicidad, dada por el filósofo poco antes de su muerte (Jaeger,

$2 \quad$ Sólo a partir de la segunda mitad del siglo XX, esta obra del estagirita ha comenzado a ser difundida en ediciones (bilingües) y traducciones en nuestra cultura latinoamericana, como las que tengo a la mano, la bilingüe de H. Rackham, Aristotle. The Athenian Constitution. The Eudemian Ethics. On Virtues and Vices. Harvard University Press. London. First published 1935. Revised and reprinted 1952. La edición bilingüe de Antonio Tovar, La Constitución de Atenas. Instituto de Estudios Políticos. Madrid, 1948. La traducción de Manuel García Valdés, Constitución de los atenienses. *Pseudo-Aristóteles, Económicos. Editorial Gredos, Madrid, 1995. En Brasil, la edición bilingüe de Francisco Murari Pires, A Constituçâo de Atenas. Editora Hucitec, Sâo Paulo, 1995. En Argentina, la traducción de Pedro Carlos Requena, La Constitución de los Atenienses. Universidad Nacional de Cuyo, Mendoza, 1997. La edición bilingüe del profesor Alberto Bernabé, Constitución de los atenienses. ABADA Editores, Madrid, 2005.

3 Los datos descriptivos de este papiro pueden seguirse en la Introducción de la edición bilingüe de Antonio Tovar, La Constitución de Atenas. Instituto de Estudios Políticos. Madrid, 1948. Además, H. García C., La Constitución de Atenas de Aristóteles: visión retrospectiva de la historia y de la institucionalidad helenas. Universidad de Chile, Santiago, 2007. Puede consultarse el estudio de G. Maddoli, Cronologia e storia. Studi comparati sull'Athenaion Politeia' di Aristotele. Perugia, 1957. 
1992: 376).

Con el riesgo que ello implica, se podría decir que la "Constitución de los atenienses" representa una síntesis de la historia de la institucionalidad política de Atenas, en que Aristóteles habría asignado un rol preponderante a la figura de Solón en ese marco histórico. ¿Cuál es ese Solón que comparece en el análisis de Aristóteles? ¿Qué le interesa al filósofo destacar? ¿Cuánto incorporó el filósofo en el marco general de su visión de los más agudos problemas políticos que abordó en su pensamiento acerca de la pólis? ${ }^{4}$.

Afirmar que Solón interesa a Aristóteles como el máximo representante del grupo de los siete sabios es sólo un aspecto del asunto, aunque como gran tema, a la vez ${ }^{5}$. Solón interesa al filósofo en cuanto representaría genuinamente una primera filosofía o teoría política consciente ${ }^{6}$ en el marco de la evolución del pensamiento de la pólis en el mundo heleno ${ }^{7}$. Y si extremamos la tesis,

$4 \quad$ Para tener una apreciación más objetiva de la importancia que tiene para Aristóteles la figura de Solón sería conveniente revisar las continuas referencias del filósofo, véase Política 1, 8, 1256b31; 2, 12, 1273 b32 y 3, 11, 1281b28; 4, 11, 1296b18; 2, 7, 1266b19; 7, 16, 1335b32 y 17, 1336b37; 4, 11, 1296a38; Retórica 1,15, 1375b32; 2, 23, 1398b16: Ética Nicomaquea 1, 10 1100a11; 10, 8 1179a9 y Ética Eudemia 2, 1, 1219b6; Metafísica 1, 2, 983a2; fragmentos 57, 143, 392, 615 en H. García C., La Constitución de Atenas de Aristóteles: visión retrospectiva de la historia y de la institucionalidad helenas. Universidad de Chile, Santiago, 2007. Puede consultarse el estudio de G. Maddoli, Cronologia e storia. Studi comparati sull'Athenaion Politeia'di Aristotele. Perugia, 1957.

Solón representa para Aristóteles "un esperimento di legislazione di importanza non trascurabile" como señala A Santoni, p. 961 ss, véase nota siguiente.

5 Remito al magnífico artículo de A. Santoni: “Aristotele, Solone e l'Athenaion Politeia", en Annali della Scuola Normale Superiore di Pisa. Vol. IX, 3. Pisa, 1979; p. 959 ss.

6 Además de las propias poesías de Solón, cfr. Plutarco, Vidas Paralelas. Solón 3. 80a. Respecto a este tema de desarrollar un pensamiento político consciente, véase el concepto de responsabilidad que ha propuesto W. Jaeger en las siempre sugerentes páginas de su Paideia: los ideales de la cultura griega: Fondo de Cultura Económica. México, tercera reimpresión, 1974, pp. 143-144.

7 El pensamiento político de Solón representa una reconstrucción e innovación de la actividad política en devenir del mundo heleno, tanto en lo teórico como en su sentido de aplicación práctica, que significó un sustantivo aporte en el marco de una verdadera revolución intelectual y sociocultural. En esta primera teoría política soloniana se pone particular énfasis -y es el fundamento de su concepción de la política- en que ésta es fruto del hombre y no obra de los dioses. Las consecuencias de este punto de vista saltan a la vista, cfr. Salvador Rus Rufino, "Análisis y teoría política en las reformas sociales de Solón de Atenas" en Rev. Foro Interno 2014, 14, p.67. Este punto de vista está claramente planteado, fundamentado en la obra de Cornelius Castoriadis, Lo que hace a Grecia. 1. De Homero a Heráclito. Seminarios 1982-1983. La creación humana II. Fondo de Cultura Económica. Argentina, 2006; 
Solón es para Aristóteles en quien halla su origen el pensamiento democrático heleno ${ }^{8}$.

En los primeros capítulos conservados, Aristóteles ha tenido especial preocupación por mostrar el contexto sociopolítico en que va a emerger el poeta y el político. Ese contexto podemos situarlo aproximadamente a partir de mediados del siglo VII a. de C. y que se va a ir caracterizando por el nacimiento y prolongado conflicto y, más exacto sería decir por una guerra civil desatada entre los "notables" y el "plêthos", el pueblo común y corriente. Se trata de la stásis, cuyo origen Aristóteles, siguiendo los versos del propio poeta, centra en el tipo de gobierno imperante. i., e., el gobierno oligárquico, al que en la Política

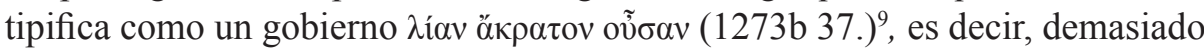
absoluto, violento, desmesurado; eso era lo que representaba tal politeía, porque en ella se permitía que los ricos esclavizaran a la gran mayoría del pueblo, que

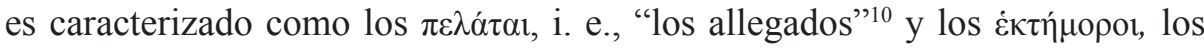
seisavos, la categoría social a la que pertenecían los que arrendaban las tierras o que trabajaban con préstamos, devolviendo la sexta parte de la producción a los $\operatorname{ricos}^{11}$. Aristóteles hace hincapié en que toda la tierra pertenecía a unos pocos $\dot{\eta}$

y del mismo autor, La institución imaginaria de la sociedad. Tusquets Editores. Argentina, 2010; además pueden consultarse una serie de artículos y conferencias referidos a la política y especialmente a la democracia en que Castoriadis vuelve a la Hélade y sus hallazgos como un germen, no como paradigma de mera imitación.

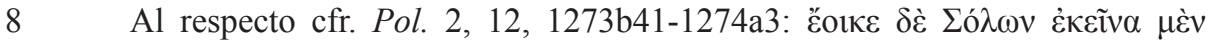

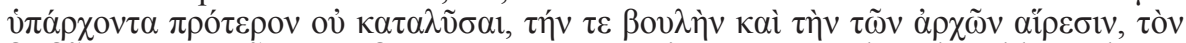

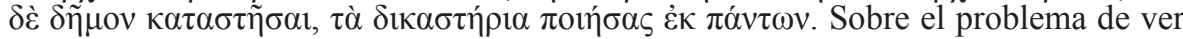
que Solón en la Política 2, 12, 1273b35-74b21 es considerado como un conservador y que en la Ath. Pol. un demócrata véase J. Dayy M. Chambers, Aristotle shistory of Athenian democracy. Berkeley, 1963, p. 74.

9 Las traducciones de los textos griegos de Aristóteles como de los fragmentos del propio Solón son de mi responsabilidad, salvo indicación contraria.

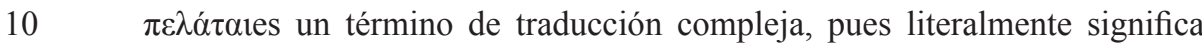
"los que se acercan, los que se aproximan" (a pedir alguna protección), por ello dependientes. En terminología romana se hablaba de "los clientes" y del sistema del "clientelismo". En Sófocles, Filoctetes 1161-2 el pelátes está muy en relación al extranjero/huésped: "Por los dioses, si alguna piedad tienes al extrajnero, acércate, / con toda benevolencia al peláta" i. e., "al allegado", al que se acerca para pedirte protección. Cfr. Platón, Eutifrón, 4 c, donde el traducctor de Gredos tradujo por "jornalero" y el traductor francés en Les Belles Lettres reprodujo como "mercenario"; no es lo mismo que un esclavo propiamente, probablemente "jornalero", que depende de un propietario, sea también una buena aproximación.

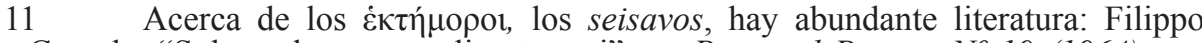
Cassola, "Solone, la terra e gli ectemori", en Past and Present $N^{\circ} 19$ (1964), pp. 26-68; José Ribeiro Ferreira, "Os hectemoros e sua situâo social” en Esclavos y semilibres en la Antigüedad Clásica, Universidad Complutense de Madrid. Madrid, 


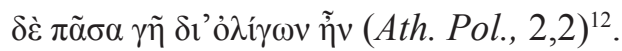

Aristóteles aplica al análisis una perspectiva económica muy básica, pero de mucho interés, para la época arcaica respecto de la política económica de la oligarquía en la incipiente evolución de los sistemas imperantes para la época y en el surgimiento primario de las póleis ${ }^{13}$. Esa política económica se basaba en que los contratos de arriendo por las tierras $(\mu i ́ \sigma \theta \omega \sigma ı)$ se efectuaban bajo el concepto de un tipo peculiar de préstamo a interés ( $\delta \alpha v \varepsilon 1 \sigma \mu o ́ \varsigma)$ en que el solicitante del préstamo comprometía "la persona", pero en rigor comprometía "los cuerpos" ( $\sigma \omega ́ \mu \alpha \tau \alpha)$, no sólo el suyo propio, y de ahí el plural "cuerpos", sino también el de sus hijos y el de su mujer ${ }^{14}$. Aristóteles informa que tal sistema, con las graves consecuencias que tuvo, existió hasta los tiempos de Solón, i., e., hasta el 594. Añade el filósofo que lo más terrible y lo más amargo para la gran mayoría fue el hecho de poder llegar a ser esclavo constitucionalmente

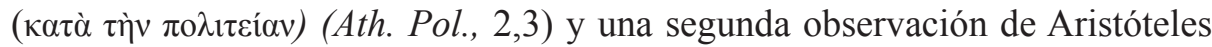

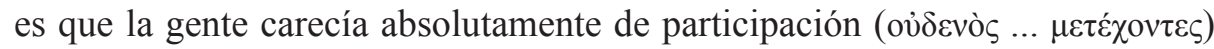
(Ath. Pol., 2,3).

Para demostrar el sistema, el filósofo hace un breve muestreo de la politeía en época arcaica anterior a Dracón. Señala que las d́ $\rho \chi \alpha i$, las magistraturas se establecieron a partir de la clase de los áristoi ( $\dot{\alpha \rho \sigma \tau i ́ v \delta \eta v) ~ y ~ d e ~}$

1990, pp. 37-53; Gretchen Schils, "Solon and the hektemoroi" en Ancient Society, ${ }^{\circ}$ 22 (1991), pp. 75-90.

12 Sin duda que este tema, el de la propiedad de la tierra, será un gran tema, presente a lo largo de la Política, donde la regulación y distribución de la propiedad se pondrá en relación con el problema de las stáseis, guerras civiles y, a su vez, con una condición propia del ser humano, a saber, el tema de la avaricia, la ambición..., y la educación, cfr. 2, 7, 1266a37-1267b21.

13 Para una perspectiva del problema de la cuestión de la economía en Aristóteles, remito al ensayo de Moses I. Finley, "Aristóteles y el análisis económico", publicado en Past and Present, $\mathrm{n}^{\circ} 47$ (1970), reproducido como último capítulo en Vieja y nueva Democracia. Ariel. Barcelona, 1980, p. 164 ss; publicado también en M. I. Finley: Estudios sobre historia antigua. Akal/Universitaria. Madrid, 1981, p. 37 ss. Compleméntese, además, con el ensayo "Economía y Sociedad en la Grecia Antigua: La obra de Moses I. Finley" de Pierre Vidal Naquet, en la antología Clases y luchas de clases en la Grecia Antigua. Akal. Madrid 1979, p. 33 ss.

14 El interesado, en el excelente libro de G. Glotz, La ciudad griega. UTEHA, México, 1957, encontrará una ajustada descripción de este problema y las consecuencias que trajo consigo para la evolución de los sistemas políticos que de allí nacieron, particularmente el nacimiento de un espíritu solidario en las clases sociales venidas a menos, véase, principalmente los apartados, orígenes y formas de la oligarquía, así como La ciudad democrática. También, por el manejo y referencia a las Fuentes, es recomendable el texto de Francisco Rodríguez Adrados, La democracia ateniense. Alianza Editorial, Madrid, 1975. 
entre los ricos ( $\pi \lambda$ oviiv $\delta \eta v)$ (Ath. Pol., 3,1), principalmente las tres magistraturas más importantes: rey, polemarco y arconte y más aun, que tenían carácter

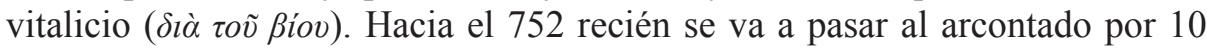
años y en 682 se reduce al ejercicio de 1 año y en forma de colegio, integrado por 9 arcontes. Por el texto de La Política nos enteramos que aún en tiempos de Solón y sus reformas, el político habría establecido todas las magistraturas a

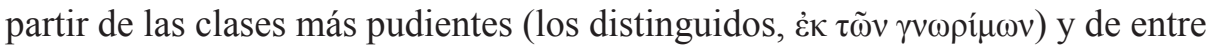

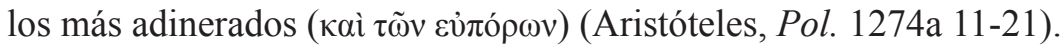

En el capítulo quinto de la Ath. Pol. hallamos las consecuencias que trajo consigo la política oligárquica, pues las leyes draconianas, si bien intentaron poner fin al derramamiento de sangre, no hicieron nada respecto al sistema usurero de los prestamistas y la injusta distribución de las tierras de labranza y allí donde impera la injusticia "se crea necesariamente -como escribe acertadamente G. Glotz- el descontento, y un descontento duradero termina siempre por suprimir lo que lo motiva" (1957: 82-83). Así, Aristóteles interpreta y comenta: "Siendo de tal naturaleza el ordenamiento en la constitución, y siendo muchos esclavos de unos pocos, el pueblo se levantó contra los notables" (Ath. Pol., 5, 1-2).

Así tuvo su origen el surgimiento de las llamadas $\sigma \tau \alpha \dot{\sigma} \sigma \varepsilon \iota \varsigma$, la guerra civil, violenta, de enfrentamientos recíprocos, durante mucho tiempo ${ }^{15}$. En medio de esta prolongada stásis, en Atenas, de común acuerdo por las partes en conflicto

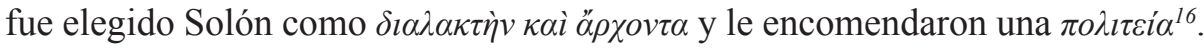

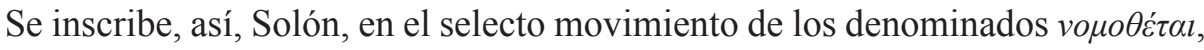
que se corresponde con ese otro movimiento social que se planteó el tema de que las leyes fueran puestas por escrito ${ }^{17}$. Este movimiento de los nomothétai, legisladores, no partió en Atenas, sino en ciudades de la Magna Grecia y de

$15 \quad$ Para este problema, el de las $\sigma \tau \alpha ́ \sigma \varepsilon 1 \zeta$, guerras civiles, revoluciones, en el mundo heleno, remito a dos textos fundamentales de Nicole Loraux, La ciudad dividida: el olvido en la memoria de Atenas. Katz Editores. Buenos Aires, 2008; La guerra civil en Atenas: la política entre la sombra y la utopía. Akal. Madrid, 2008; en ambos textos se encontrará abundante y actualizada bibliografía al respecto; JeanPierre Vernant (dir.), Problèmes de la guerre en Grèce ancienne. Paris. École des Hautes Études en Sciences Sociales, 1985; Giorgio Agamben, Stasis. La guerra civile come paradigma politico. Homo sacer II, 2 Turín, Bollati Boringhieri, 2015.

16 Para el detalle de cada una de estas denominaciones véase Salvador Rus Rufino, op. cit., nota ocho, p. 69.

17 Respecto de los vouofćtal, legisladores, véase Nicholas G.L. Hammond, "The Dates of Solon's Seisachtheia and Nomothesia", Cambridge Philological Society, ${ }^{o}$ 169-171 (1938), del mismo autor en The Journal of Hellenic Studies, № 60 (1940) pp. 71-83. 
Sicilia. Aristóteles, en Política nos informa a lo menos de dos importantes legisladores: Zaleuco entre los locrios occidentales, quien hacia el 663/2 dio un código a sus ciudadanos. Unos treinta años más tarde, Carondas dio a sus conciudadanos de Catania otro código de leyes y también - dice Aristóteles- a otras ciudades calcídicas de Italia y de Sicilia ${ }^{18}$.Sin duda, la publicación de las leyes trajo consigo cambios. Pero el más significativo, es decir, el hecho que las leyes fueran conocidas por todos y sancionadas por la ciudad "marcaba una época en la historia del Derecho" - como dice Glotz.

Aristóteles, como hemos señalado ya, recurre como fuente directa a las elegías y a los yambos de Solón, asistimos, así, al modo cómo Aristóteles no sólo reconoce un significativo valor a la poesía, sino también y, sobre todo, al modo cómo él interpreta estos testimonios y los contenidos que rescata y, con ello, la figura política del poeta, que parte con la designación que le dieron al elegirlo, pues lo nombraron como un diallaktēs, además de arconte. La palabra $\delta l \alpha \lambda \lambda \alpha \kappa \tau \eta$ $\varsigma$ ha sido traducida frecuentemente como "árbitro" y mejor aún como "mediador". "Árbitro" en su sentido latino viene a representar para nosotros al “juez”, esto es, la figura de un soberano absoluto. Sin embargo, en griego alude a la persona que logra poner de acuerdo, especialmente de partes en conflicto, que hace cambiar los sentimientos y por lo tanto el carácter (hay un efecto paidético sobre el $\tilde{\eta} \theta$ o $\varsigma$ (èthos). Por ello, el mejor sentido de la palabra sería algo así como "conciliador", "reconciliador", sentido que parece cobrar mayor fuerza en la interpretación del estagirita: un mediador que busca la reconciliación donde el odio ha generado la distorsión y el desequilibrio social, la ruptura de lo que es la pólis en tanto que comunidad. Lo que el filósofo va a destacar es esta calidad de colocarse como un verdadero mediador contra unos y otros; disputar a favor de unos y otros y estar en desacuerdo con unos y otros; desde este principio fundamental de autoridad ética, Solón pudo exigir a las partes en conflicto que

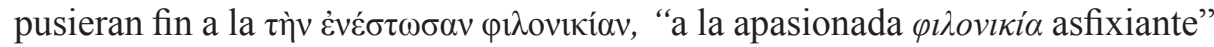
(Ath. Pol., 5,2), causante de la plena decadencia de la pólis. La philonikía a la que se refiere aquí, Aristóteles, alude aquí al sentido negativo del término, al deseo de vencer el uno al otro, el amor por la victoria, el gusto por la riña, la rivalidad, la envidia ${ }^{19}$. Aristóteles interpreta que la elegía tendría por objeto la

18

Pol.2, 12, 1274a22-30.

19 Confróntese el uso negativo en fuentes tales como Tucídides I, 42 y III, 82; Demócrito 237; Platón Leyes 860 d, 938 c, Gorgias515 b, Alcibíades 122 c; Lisias 3. 43 y 33.4; Isócrates 12, 158; Demóstenes 9.14, cf Platón, Timeo88 a y 90 b, República 548 c; Aristóteles, Pol. 1308 31; Ev. Lucas 22. 24; el uso positivo como competencia, emulación en Platón, Leyes 834 c; Jenofonte, Ciropedia 7.1.18 y 8.2.26, Anábasis 4.8.27. 


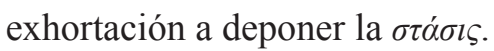

Para descubrir lo originariamente solónico, el estagirita opera metodológicamente recurriendo a los contraste, a las analogías. Así, por ejemplo, nos presenta a un Solón privilegiado por la cuna de nacimiento, gozando de una buena reputación lo que le llevaba a ocupar un primerísimo lugar, quizás por su sapiencia y el renombre que ya ha alcanzado al formar el selecto grupo de los siete $\operatorname{sabios}^{20}$, en quienes prima una especial sabiduría práctica, presente en la formación de un ēthos antrópico. Para Aristóteles, Solón es un hombre de clase media, pese a su cuna aristocrática por la hacienda que poseía y los negocios personales. Esta referencia a la clase media de Solón parece tener mucha más relevancia que la que a primera vista parece. Pareciera que lo que Aristóteles quiere relevar en la figura del poeta es un estatus ético de moderación y prudencia que lo eleva por sobre su propia clase social y desde esa posición privilegiada se permite exhortar, aconsejar y reprender a la

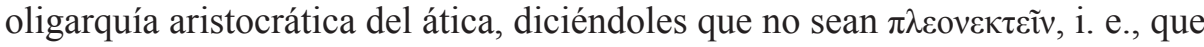
no sean rapaces, codiciosos: "Y vosotros, habiendo apaciguado en los pechos al fuerte corazón, quienes de muchos bienes llegasteis hasta la saciedad, en cosas moderadas poned el altanero nous; porque ni nosotros os obedeceremos, ni vosotros tendréis estas cosas a vuestro antojo" (Ath. Pol., 5,3 y 4D; I, 4 Rodríguez Adrados) $)^{21}$.

Apoyándose en el fragmento de esta elegía y en otros, Aristóteles comenta que Solón echa la culpa de la stásis a los plousioi, los ricos a causa de su 'amor a la riqueza' ( $\varphi$ i $(5,3)$, porque en este comportamiento radica el origen de la odiosidad. La guerra civil, pues, no es otra cosa que la manifestación real y concreta del odio $\left(\varepsilon^{\prime} \chi \rho \rho \alpha\right)$. Los versos de esta elegía encerrarían una especie de programa político. Por lo tanto, junto con otros fragmentos que cita también el estagirita y muy especialmente la Eunomía ${ }^{22}$ corresponderían al período inmediatamente

$20 \quad$ Para el tema de los siete sabios véase Plutarco, Vidas Paralelas, Solón IIIIV, en Biógrafos griegos. Aguilar. Madrid, 1964 pp. 114-115; Diógenes Laercio, I, 45, en Vidas de los filósofos ilustres. Editorial Alianza, Madrid, 2011, p. 54 ss.; M. L. Paladini, Influenza della tradizione dei Sette Savi nella vita di Solone di Plutarco; REG, LXIX, 1956, pp. 377-411; A. Santoni, "Aristotele, Solone e L' Athenaion Politeia, en Annali della Scuola Normale Superiore di Pisa, vol.IX, 3, 1979, pp. 964 ss.

21 Acerca de este problema de la insaciedad, la voracidad como avaricia,

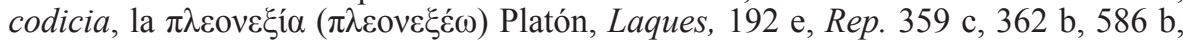
Eut. 15 a; Gorg. 483 c, Tim. 82 a; Jenofonte, Mem. 2. 6. 21; Tuc. 4.62 cf. 86; Arist. Ret.1360 a 3, 1402 b 25, Heródoto 7. 149; Arist. Elenc. Sof. 175 a 19, Pol. 1297 a 11. 22 He presentado mi traducción completa de este poema en H. García C., Poesía 
anterior o cercano al arcontado y constituyen un grupo de fragmentos en que prima la mirada de diagnóstico de la realidad por parte de Solón. De modo que una mirada global de esta elegía permitirá apreciar con más claridad los acentos que ha puesto el filósofo en su interpretación.

La elegía Eunomía se abre con una afirmación radical: la stásis que lleva a la pólis a su desmoronamiento no radica en el destino ( $\alpha \tilde{i} \sigma \alpha)$, ni en los $\varphi \rho \varepsilon ́ v \varepsilon \varsigma$, i., e., pensamientos, voluntades, intenciones de los dioses. Introduce, así, Solón, un giro radical en la concepción teológica de la época. Su diagnóstico de la realidad se funda exclusivamente en el obrar humano ${ }^{23}$ :

Pero los propios ciudadanos destruir la gran ciudad con sus insensateces quieren, por las riquezas seducidos, y la injusta manera de pensar de los conductores del pueblo

$$
\text { (Solón, I, 4, vs. 5-7) } 24
$$

El poeta insiste en su mirada diagnóstico: que los 'seducidos por las riquezas' cometen acciones injustas, de modo que este modo de enriquecerse

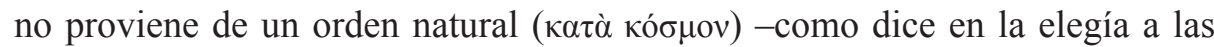
Musas, sino bajo la figura del abuso (v่ $\varphi$ ’óßpıs) (Solón, I, 13 vs. 10-11). Abuso e injusticia en Solón van de la mano. Lo que denuncia Solón en esta elegía no

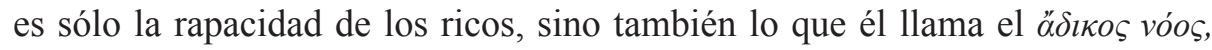
i. e., 'la injusta manera de pensar, las inicuas intenciones' de los conductores del pueblo (Ath. pol., 3,7). El acento está puesto, pues, en los propios

lírica griega arcaica del siglo VII a. C. Antología de fragmentos de Arquíloco a Anacreonte. Centro de Estudios Griegos Bizantinos y Neohelénicos, U. de Chile. Santiago, 1998, pp. 51-53, véase además H. García C., La Constitución de Atenas de Aristóteles: visión retrospectiva de la historia y de la institucionalidad helenas. Centro de Estudios Griegos Bizantinos y Neohelénicos, U. de Chile. Santiago, 2007, pp. 80-83.

23 Cfr. Salvador Rus Rufino, op. cit., p. 67 y para su vinculación con el movimiento religioso de la época y de los Siete Sabios Plutarco IV en Biógrafos Griegos, op. cit., p. 115; R. O. Bloch, “Aristote appelle sophistes les Sept Sages", RPh, CI, 1976, pp. 129-164; además, para una ampliación del tema religioso Atenas y Eleusis cfr. Louise_MarieL 'Homme Wéry, "La notion de patrie dans la pensée politique de Solon", en L'antiquité classique, tome 69, 2000, pp 21-41.

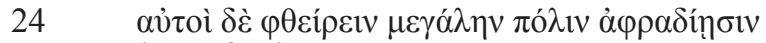

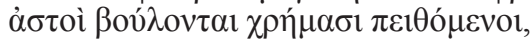

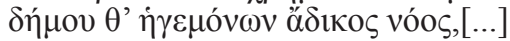


conciudadanos como los responsables directos de la situación decadente. "Con ello, de modo sorprendente -comenta Hermann Fränkel -la responsabilidad queda sustraída a los dioses y atribuida a los hombres" (1993:214). Aunque esta idea soloniana no sea original, tiene el mérito de zanjar la ambigüedad homérica y sentar definitivamente y con claridad que en asuntos humanos, la aíía, la responsabilidad en lo que respecta a la pólis es únicamente humana y ante el diagnóstico de la enfermedad, tal será también el remedio: asumir tal responsabilidad, el destino, en sus propias manos. Que esta convicción de Solón estuvo al centro de su teoría política es refrendada cuando recrimina a sus conciudadanos por la instauración de la tiranía de Pisístrato, pese a sus advertencias: "Y si habéis sufrido cosas dolorosas a causa de vuestra vileza, no achaquéis a los dioses la moira de éstas" (Rodríguez, frag. 8).

Esta capacidad del poeta-político de detectar con objetividad los principios y causas que llevan al declive y a la autodestrucción de la comunidad política es la que hace de Solón un pensador político, y quizás, Aristóteles tácitamente lo vea como el primer teórico político, pues habría sabido armonizar racionalmente un conjunto de reformas que pretendían atacar la "herida inevitable". El poema de la Eunomía, como en un cuadro, nos muestra dos facciones en disputa: por un lado, la de los ricos, de clase noble, en quienes radican las responsabilidades políticas, pero que manipulan y quebrantan el nómos para su propio beneficio y, por otro lado, los representantes del démos, carentes de responsabilidades públicas, pero que como facción agraviada no tiene un proyecto, una inteligencia clara para enfrentar la adversidad. Pese a la laguna que hallamos en el fragmento, el sentido de los versos que siguen es manifiesto y re-suenan tan contemporáneos a nuestros oídos cuando se refiere a los rapaces saqueadores:

\section{[...] y se enriquecen, seducidos por obras injustas}

ni de las propiedades sagradas y no teniendo ninguna consideración por las públicas roban por saqueo unos de un lado, otros, de otro, ni se preocupan de los sagrados fundamentos de la justicia, la cual, callada, conoce las cosas presentes y las pasadas, y con el tiempo llega de todas formas para vengarse. Esto para toda la ciudad llega como una herida inevitable, y rápidamente va a parar en una nefasta esclavitud, que la revolución civil y la guerra dormida despierta, la cual ha aniquilado la amada juventud de muchos, pues a causa de los malintencionados rápidamente la muy amada ciudad se desgasta en asociaciones políticas, apreciadas por los que hacen cosas injustas. Estas cosas en el pueblo 
se tornan perniciosas, $y$ de entre los pobres llegan muchos a tierra extranjera vendidos, con cuerdas indignas atados, y los vergonzosos trabajos de la esclavitud soportan por fuerza (Edmonds I, 4, 13-26).

Para Solón la deducción en su diagnóstico es evidente: tal situación es el resultado de una politeía que es una $\Delta v \sigma v o \mu$ ía, un pésimo régimen político (id. 32) que ha afectado a los hombres tanto individual como colectivamente. Ha hecho surgir una nueva forma de esclavitud y el exilio, producto de la venta del ser humano convertido en una mera mercancía. Pero con ello se ha afectado

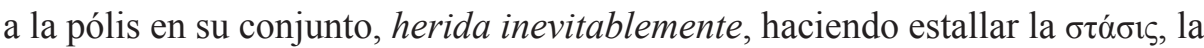
revolución civil. El principio general que deduce Solón es que, por el contrario, la Ev̉vouía reconstruye, ajusta y clarifica, en medio de la incertidumbre, el tejido social. Una correcta $\pi$ o $\lambda \imath \tau \varepsilon i ́ \alpha$ pone en su lugar a los injustos, suaviza las

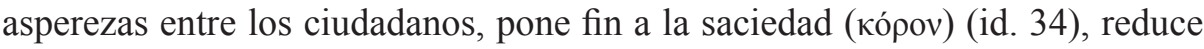

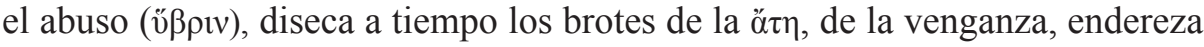

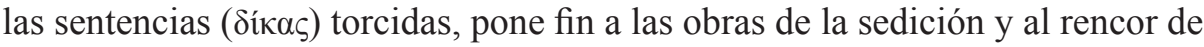
la terrible discordia.

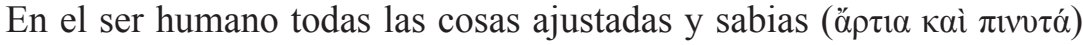
dependen de la Ev̉vouía, i., e., del ejercicio correcto de la ley. Solón -como ha escrito W. Jaeger- funda su fe política en la fuerza de Díke, en la misma fe del derecho que ya había anticipado Hesíodo. Sin embargo, al acentuar Solón que la disnomía no es un problema divino, sino propio del hombre, por más que haya una interrelación con el ámbito divino, que no lo niega el poeta, ponía una idea central en su visión teórico-política: que la política es fruto de los hombres que vivimos en pólis y, por ende, de ahí depende también el darle forma o reformar las instituciones que preservan la comunidad política. La clave -como ha escrito el profesor Salvador Rus en su bello trabajo acerca de Solón, en 2014 - está en:

Formar y desarrollar la capacidad racional, la inteligencia (noûs) con la que uno es capaz de tomar conciencia del entorno, comprender las situaciones, encontrar soluciones a los problemas, construir la polis, proceder a reformarla y a redactar leyes que tengan como base la justicia

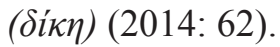

Volviendo a Aristóteles, podemos comprender mejor los capítulos que hablan de las medidas políticas adoptadas por Solón como arconte entre 594/3 a. de C., fueron medidas políticas de emergencia, que en su tiempo fueron,sin 
duda, las más revolucionarias, el filósofo las resume en tres, que a su juicio fueron las más populares ( $\tau \grave{\alpha} \delta \eta \mu о \tau \imath \kappa \omega ́ \tau \alpha \tau \alpha)$ :

- Liberación del pueblo en el presente y para el futuro, prohibiendo los préstamos en que se ponía el mismo deudor como fiador.

- Dictó la ley de cancelación de las deudas, la $\sigma \varepsilon ı \sigma \alpha ́ \chi \theta \varepsilon \imath \alpha$. Eso fue lo que hoy conocemos como condonación de las deudas ${ }^{25}$.

- Dio un nuevo ordenamiento a la politeía, partiendo por la clasificación de las clases sociales, basándose en un censo de rentas.

Además, lo novedoso en el ordenamiento del régimen político, más allá de los cargos que se configuran, es que éstos no se designan a dedo como lo hacía la oligarquía tradicional, que los designaba, además, exclusivamente, de entre la clase aristocrática, en especial las tres magistraturas más importantes: rey, polemarco y arconte. Ahora Solón hizo que las magistraturas fueran asignadas por sorteo ( $\kappa \lambda \eta \rho \omega \tau \alpha \dot{s})$ (Ath. Pol., 8,1) entre candidatos que habían sido seleccionados previamente. Hay que sumar a esto que el solo hecho de haber permitido la incorporación de los más desposeídos de la sociedad, los thetes ${ }^{26}$, en la participación de actividades claramente políticas como su incorporación en los tribunales y en la asamblea es un hecho que marca un hito, que luego sería reconocido como aporte decisivo hacia la conquista democrática, en Atenas.

En Política, Aristóteles nos informa que Solón facilitó que el dêmos tuviera presencia al hacer que todos participasen en los tribunales( $\tau$ òv $\delta \dot{\varepsilon} \delta \tilde{\eta} \mu \mathrm{ov}$

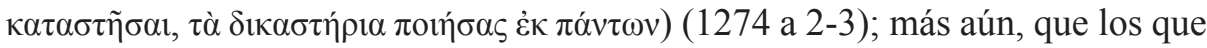
participasen fueran nombrados por sorteo. Con el tiempo los tribunales se fueron haciendo poderosos; aspecto que Atistóteles critica, diciendo que el pueblo en su tiempo ha llegado a ser halagado como un tirano y cuya transformación

25 Respecto de la $\sigma \varepsilon ı \sigma \alpha ́ \chi \theta \varepsilon ı \alpha$, descarga, eliminación (Condonación de deudas) Plutarco XVen Biógrafos Griegos op. cit., p. 121. Diógenes Laercio 45; Frank J Frost, "Attic Literacy and the Solonian Seisachtheia": The Ancient Word, no 15/3-4 (1987), pp. 51-58; Nicholas G.L Hammond, "The Seisachtheia and the Nomothesia of Solon" The Journal of Hellenic Studies, N ${ }^{0} 60$ (1940), pp. 71-83, del mismo autor cfr. su artículo: "Land Tenure in Attica and Solon's Seisachtheiai": The Journal of Hellenic Studies, $n^{\circ} 81$ (1961), pp. 76-98. Salvador Rus Rufino, op. cit. P. 73 ss y nota a pie $\mathrm{n}^{\circ}$ 25.Cfr. Además, José Fernández Ubiña "Aspectos sociales de Grecia Arcaica”, en Clases y luchas de clases en la Grecia Antigua, op. cit., pp. 95-96.

26 Acerca del problema de los $\theta \tilde{\eta} \tau \varepsilon \varsigma$ (thetes) en el marco de la vida del trabajo en el mundo heleno véase Hom. Od. 4. 644; Hes., Erga.602; Pl., Pol. 290a; Arist., Pol., 1278a 13, Ath. Pol., 7. 3; Tuc., 6. 43. Además, M. I. Finley "Riqueza y trabajo", en El mundo de Odiseo. Breviarios del F.C.E. México, 1961, pp. 60-64 y su artículo "La servitude pour dettes", en Rev. Hist. De droit franç. Et étr., XLIII (1965), 159-184; G. Glotz, La ciudad griega, op. cit., pp. 30-31, 88, 102, 107, 179. 


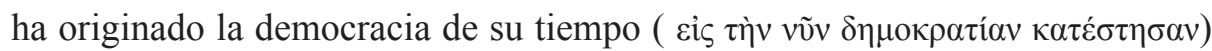
(1274 a 6-7).

Podríamos sostener que aunque Solón nunca tuvo en mente la evolución que señala Aristóteles, puso, no obstante un elemento germinal para el desarrollo de una actividad política más democrática.

Aristóteles ha destacado las tres leyes que a su juicio son las más importantes para el pueblo. Pero cabría referir por contexto dos leyes que a nuestro juicio son complementarias y acordes con las ya referidas. Se trata de la denominada ley de $\varepsilon i \sigma \alpha \gamma \gamma \varepsilon \lambda i$, , esto es, "denuncia por conspiración”, que consistía en denunciar públicamente "a los que conspiraban por el derrocamiento del

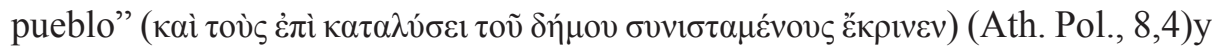
cuya supervisión estaba en manos del nuevo Consejo reformado, especialmente el de los Aeropagitas. Sin duda se trataba de una medida protectora de la gente común y corriente que paulatinamente iban asumiendo un rol más protagónico en lo político. La ei $\sigma \alpha \gamma \gamma \varepsilon \lambda i \alpha$ significaba una acusación de alta traición contra la seguridad de la pólis, que con el tiempo se fue transformando en arma peligrosa, entre otras cosas, por la indeterminación de los actos que merecían tal querella y se hizo abuso político (Glotz, 1957,142/280).

En esta misma perspectiva de diagnóstico que implementa Solón, Aristóteles comenta le llevó a plantear otra ley, pues el poeta se habría percatado que en las stáseis algunos ciudadanos no participaban de los eventos, conformándose "con lo que buenamente resultase de ellas"- según la traducción

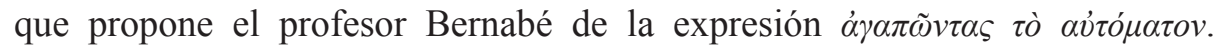
Aristóteles atribuye como causa de esa marginación de los ciudadanos a la

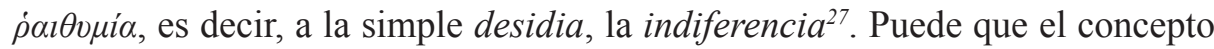
lo haya usado el mismo Solón. En concreto la ley en cuestión fue la ley de

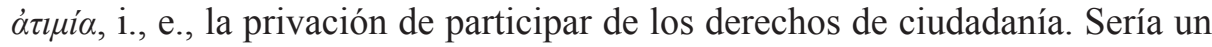
átimos todo aquel ciudadano que en una guerra civil no tomara las armas en favor de uno u otro bando. De modo que el ciudadano para evitar la exclusión de la comunidad política se vió obligado a adscribirse a alguno de los partidos o facciones en disputa. Investigadores modernos han interpretado esta ley como que Solón estableción el principio de que la pólis debía ser dirigida por todos los ciudadanos en colaboración.

Aunque sea sólo de pasada, conviene referir que hay otras fuentes que complementan esta ley de atimía, como Diógenes Laercio, por ejemplo, quien

27 Para ampliar y precisar esta visión política desde Solón y otros Arist., Ath. Pol., 8.5; Lisias, 10.11; Jen., Mem., 3.5.5; Demóstenes, 9.5; Eur., Med., 218; Plat., Fed., 99b, y Teet., 166b. 
nos informa que esta ley no tuvo aplicación sólo en lo político en estricto sentido, sino también en lo que podríamos llamar en el ámbito humano-familiar, pues la ley consideró ö́tıo a todo aquel que no se ocupara de alimentar a sus padres, por cualesquiera fueran las razones; y la misma ley se aplicó a todo aquel que despilfarrara la hacienda o el patrimonio de los padres; Diógenes Laercio dice:

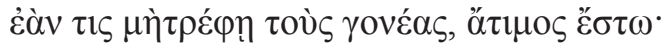

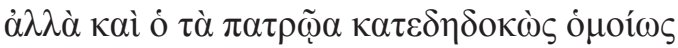

"Si alguien no alimentara a sus padres, sea deshonrado (privado de los derechos de ciudadano), pero también el que haya devorado la herencia de los padres"

(Diogenes Laertius, Vol. I,55)

\section{A modo de conclusiones provisorias.}

Aristóteles ha puesto la reflexión y el ejercicio político de Solón como eje central del desarrollo del pensamiento y de la teoría política, pues el poeta habría integrado la racionalidad al diagnóstico de los fenómenos sociales. Por lo mismo, la actividad política y sus consecuencias son única y exclusivamente responsabilidad humana y no de los dioses. Las consecuencias que tal perspectiva tiene en el devenir son fundamentales, son el germen para el desarrollo no sólo de los problemas políticos en estricto sentido, sino para la ética que devino conjuntamente.Las medidas políticas que Aristóteles ha señalado como las más populares, en el marco del diagnóstico soloniano de la realidad social, así lo demuestran: crítica y ruptura con el abuso y la inhumanidad del esclavismo por deudas, aunque ello no implica la superación de la esclavitud; posibilidad de exigir reparación por los agravios y derecho de apelación ante los tribunales son aspectos no sólo reformadores, sino aspectos innovadores genuinos que modelarán un nuevo imaginario en el devenir del derecho heleno, que se instala en Occidente desde aquel imaginario soloniano hasta hoy.

El posterior desarrollo de estas ideas implicó que el démos se hiciera fuerte hasta el extremo de hacerse kyrios de la politeía y la razón es porque, a su vez, el démos es kyrios, dueño del voto.

Aristóteles ha recogido la dóxa a la que él tenía acceso y que en muchos casos comparte, particularmente, de lo último señalado. El filósofo tiene en la más alta estima la obra del poeta. Ha valorado, esencialmente, es decir, objetivamente, la poesía política de Solón. De modo que la interpretación 
que nos presenta es perfectamente verificable no sólo en la obra directa del poeta, sino también en las fuentes que el estagirita conoció de primera mano en las investigaciones que tenía en curso en el Liceo. Esa misma alta estima por el poeta se puede corroborar en la Política y siempre referida a cuestiones fundamentales de las causas que originan el desarrollo de determinada institucionalidad, por ejemplo, las causas de las stáseis y la regulación de la propiedad. Otra prueba manifiesta de esta alta estima por la figura de Solón está en la defensa que Aristóteles, ante los ataques al poeta político, realiza, particularmente la habladuría que surgió después de aplicada la seisáchtheia, la condonación de las deudas.

Solón es ya para Aristóteles el genuino germen de la teoría política de la democracia ateniense. Es radical su opinión, expresada en La Política: tòv

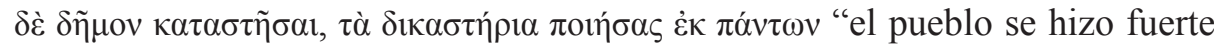
cuando [Solón] hizo que los tribunales fueran de todos" (1273b 53-1274a 4). Traductores como Julián Marías y María Araujo han dado a entender que Solón "implantó la democracia".

Para concluir cabría decir que Aristóteles ha cerrado su interpretación del pensamiento y teoría política de Solón, citando literalmente una selección de fragmentos de los poemas (elegías y yambos) del propio poeta, e incluso cita un poema completo que bien puede considerarse como la síntesis de toda la actividad política del sabio Solón; con lo cual, metodológicamente, el estagirita refrenda su propia investigación, mostrando con ello no sólo que la poesía tiene un profundo valor histórico y mostrativo de la realidad, sino también rindiendo un tributo al poeta y político.

Cito por la traducción de mi estimado colega Alberto Bernabé para cerrar esta investigación y tributo aristotélico: texto que encierra un contenido y una problemática tan contemporánea:

Y yo, de los asuntos por los que convoqué al pueblo, ¿en cuál de ellos cejé antes de lograrlo?

Podría dar fe de ello, ante el tribunal del tiempo,

la gran madre de los dioses del Olimpo, mejor que nadie, la negra Tierra, a la que entonces

le saqué yo los mojones hincados aquí y allí, antaño sierva y ahora libre.

Y a muchos a Atenas, a su patria, fundada por los dioses, los traje de regreso, después de haber sido vendidos, el uno, contra ley, 
el otro, legalmente; y a otros que por la perentoria necesidad habían huido y que la lengua ática no usaban ya, de tanto vagar de un lado a otro. Y a los que allí padecían indecorosa servidumbre, temerosos de los cambios de humor de sus señores los hice libres. Tales medidas por mi autoridad, tras haber armonizado por igual firmeza con justicia, las puse en práctica, y hasta el fin llegué, como había prometido.

Escribí leyes por igual para el vil que para el noble, adecuando a cada uno una justicia recta. al haber tomado en sus manos la aguijada que yo tuve atro hombre sin luces y ansioso de ganancias, no habría sabido contener al pueblo. Pues si yo hubiese accedido a lo que por entonces proponían los de un bando, o, por el contrario,, a lo que los otros maquinaban contra ellos, de muchos hombres habría quedado ya viuda la ciudad. Por todo ello, de aquí y de allá sacando fuerza de flaqueza, Me revolví como un lobo entre un tropel de perras. (Ath. Pol., 12, 4).

\section{REFERENCIAS BIBLIOGRÁFICAS FUENTES, EDICIONES, TRADUCCIONES}

\section{ARISTÓTELES,}

RACKHAM, H. (1935), Aristotle. The Athenian Constitution. The Eudemian Ethics. On Virtues and Vices. Harvard University Press. London. First published. Revised and reprinted 1952.

TOVAR, ANTONIO (1948), La Constitución de Atenas. Instituto de Estudios Políticos. Madrid.

- (1971), Retórica. Instituto de Estudios Políticos. Madrid.

MANUEL GARCÍA VALDÉS (1995), Constitución de los atenienses. *PseudoAristóteles, Económicos. Editorial Gredos, Madrid.

FRANCISCO MURARI PIRES (1995), A Constituçâo de Atenas. Editora Hucitec, Sâo Paulo.

PEDRO CARLOS REQUENA (1997), La Constitución de los Atenienses. Universidad Nacional de Cuyo, Mendoza.

ALBERTO BERNABÉ (2005), Constitución de los atenienses. ABADA Editores, Madrid. 
ARAUJO M., MARÍAS J. (2014), Ética a Nicómaco. Edición bilingüe. Centro de Estudios, Políticos y Constitucionales.10 edición, Madrid.

MARÍAS, J., ARAUJO, M. (1983), Política. Edición bilingüe. Centro de Estudios Constitucionales. Madrid.

PLUTARCO (1964), Vidas Paralelas. Biógrafos griegos. Aguilar. Madrid.

DIÓGENES LAERCIO (2011), Vidas de los filósofos ilustres. Editorial Alianza, Madrid.

\section{COMPLEMENTARIA}

MATHIEU, G. (1915), Aristote. Constitutiond'Athènes. Essai sur la méthodesuivie par Aristote dans la discussion des textes. Paris.

WEIL, R. (1964), "Philosophie et Histoire. La vision de l'histoirechez Aristote", en Entretiens sur l'antiquité classique, XI, Vandoeuvres-Genève. Fond. Hardt [1965].

JAEGER, W. (1992), Aristóteles: bases para la historia de su desarrollo intelectual. Fondo de Cultura Económica. México, segunda reimpresión.

- (1974), Paideia: los ideales de la cultura griega: Fondo de Cultura Económica. México, tercera reimpresión.

GARCÍA, H. C. (2007), La Constitución de Atenas de Aristóteles: visión retrospectiva de la historia y de la institucionalidad helenas. Universidad de Chile, Santiago. - (1998), Poesía lírica griega arcaica del siglo VII a. C. Antología de fragmentos de Arquíloco a Anacreonte. Centro de Estudios Griegos Bizantinos y Neohelénicos, U. de Chile. Santiago.

MADDOLI, G., Cronologia e storia. Studi comparati sull'Athenaion Politeia' di Aristotele. Perugia, 1957.

SANTONI, A. (1979): “Aristotele, Solone e 1'Athenaion Politeia”, en Annali della Scuola Normale Superiore di Pisa. Vol. IX, 3. Pisa.

SALVADOR RUS RUFINO, (2014): “Análisis y teoría política en las reformas sociales de Solón de Atenas". Rev. Foro Interno n ${ }^{\circ} 14$.

CASTORIADIS, C. (2006), Lo que hace a Grecia. 1. De Homero a Heráclito. Seminarios 1982-1983. La creación humana II. Fondo de Cultura Económica. Argentina.

- (2010), La institución imaginaria de la sociedad. Tusquets Editores. Argentina.

CASSOLA, FILIPPO, (1964): “Solone, la terra e gliectemori”, en Past and Present $\mathrm{N}^{o}$ 19.

RIBEIRO FERREIRA, JOSÉ, (1990): "Os hectemoros e suasituâo social”. Esclavos y semilibres en la Antigüedad Clásica, Universidad Complutense de Madrid. Madrid.

SCHILS, GRETCHEN (1991):"Solon and the hektemoroi”. Ancient Society, nº 22. 
FINLEY, MOSES I. (1980), Vieja y nueva Democracia. Ariel. Barcelona. - (1970): “Aristóteles y el análisis económico", publicado en Past and Present, $\mathrm{N}^{\mathrm{o}} 47$

- (1981), Estudios sobre historia antigua. Akal/Universitaria. Madrid.

- (1961), El mundo de Odiseo. Breviarios del F.C.E. México.

- (1965): "La servitude pour dettes", en Rev. Hist. De droit franç. Et étr., XLIII.

VIDAL NAQUET, PIERRE (1979): "Economía y Sociedad en la Grecia Antigua: La obra de Moses I. Finley" en la antología Clases y luchas de clases en la Grecia Antigua. Akal. Madrid.

GLOTZ, G., (1957), La ciudad griega. UTEHA, México.

LORAUX, N. (2008), La ciudad dividida: el olvido en la memoria de Atenas. Katz Editores. Buenos Aires.-(200), La guerra civil en Atenas: la política entre la sombra y la utopía. Akal. Madrid.

HAMMOND, N. G. L.(1938): "The Dates of Solon's Seisachtheia and Nomothesia”, Cambridge Philological Society, $n^{\circ}$ 169-171.

RODRÍGUEZ ADRADOS, F. (1975), La democracia ateniense. Alianza Editorial, Madrid.

BLOCH, R. O. (1976): “Aristoteappelle sophistes les Sept Sages”, RPh, CI.

FROST, FRANK J. (1987): "Attic Literacy and the Solonian Seisachtheia": The Ancient Word, $\mathrm{N}^{\mathrm{o}} 15 / 3-4$.

HAMMOND, NICHOLAS G.L. (1940), "The Seisachtheia and the Nomothesia of Solon" The Journal of Hellenic Studies, $N^{\mathrm{o}} 60$.

- (1961): "Land Tenure in Attica and Solon's Seisachtheiai": The Journal of Hellenic Studies, $\mathrm{n}^{\circ} 81$. 